\title{
The mediating effect of literacy of LMS between self-evaluation online teaching effectiveness and self-directed learning readiness
}

\author{
JeongChul Heo ${ }^{1} \cdot$ Sumi Han ${ }^{2}$
}

Received: 16 March 2021 / Accepted: 17 May 2021 / Published online: 3 June 2021

(c) The Author(s), under exclusive licence to Springer Science+Business Media, LLC, part of Springer Nature 2021

\begin{abstract}
The aim of this study was to analyze whether the self-evaluation online teaching effectiveness (SEOTE) and literacy of learning manage system (LLMS) did significantly have effect on the level of self-directed learning readiness (SDLR). Furthermore, it was another purpose to examine whether the LLMS was a significant mediating effect between SEOTE and SDLR. Pearson correlation, multiple linear regression, and mediated regression analysis were conducted for this study. This study included 210 online college students in Korea who responded to three websurvey questionnaires (SEOTE, LLMS, and SDLR). The bivariate (Pearson) correlation analysis showed that SEOTE significantly influenced on SDLR $(r=524, p<.01)$ and LLMS was positively associated with SDLR $(r=487, p<.01)$. The multiple linear regression revealed that SEOTE and LLMS significantly predicted SDLR and explained $31.4 \%$ of variance in SDLR. The results of mediated regression analysis revealed that LLMS did have a significant indirect or mediating effect with SEOTE in predicting SDLR.
\end{abstract}

Keywords Self-Evaluation Online Teaching Effectiveness (SEOTE) · Literacy of Learning Manage System (LLMS) · Self-directed Learning Readiness (SDLR) • Online Education

\section{Sumi Han}

hsumi@hanmail.net

1 E-Learning Center, Sehan University, Dangjin-si, Chungnam, Korea

2 Counseling Psychology Department, Seoul Cyber University, Seoul, Korea 


\section{Introduction}

The total number of students at four-year online universities in Korea has steadily increased from 109,466 in 2014 to 121,882 in 2019 (Cyber University Information, 2019). The number of public courses on the K-MOOC (Korean Massive Open Online Course) platform has increased from 27 courses in 2015 to 999 courses in 2019. In addition, the number of enrolled K-MOOC students that are only 55,000 in 2015 reached 1.6 million in 2020 (Ministry of Culture, Sports and Tourism, 2018; National Institute for Lifelong Education, 2021).

Allen and Seaman (2016) found that in 2015, the number of college students who are taking more than one online class was up 3.9 in U.S. higher education compared to the previous year. There were more than 2.8 million students taking all their classes at a distance in the fall of 2014 and this figure represented $14 \%$ of all college students (Allen \& Seaman, 2016). The number of students having distance education is a growing segment. In addition, the percent of higher education institutions that currently have a MOOC (Massive Open Online Course) had increased from $2.6 \%$ in 2012 to $5.0 \%$ in 2013, to $8.0 \%$ in 2019, and to $11.3 \%$ in 2015 (Allen \& Seaman, 2016). Cyber universities and open online courses will continue to grow due to the dramatic advances in the internet and information technologies, with a convenient educational environment and very affordable tuition fees for students.

The self-directed or independent learning tends to be more demanding in online education and learning, and learners are expected to play an active role, selfregulate their learning paces, and engage in more interactively (Hematian et al., 2017; Howell et al., 2003; Lemmetty \& Collin, 2019; Sirakaya \& Ozdemir, 2018). The self-directed learning (SDL) skills can be significantly predictive of academic achievements and outcomes which online students can develop by finishing their online course works (Zimmerman \& Kitsantas, 2005). Therefore, SDL skills are very important educational concept to become a successful learner in online education (Rivenburg, 2015).

In other words, self-directed learners complete their online courses independently and autonomously in a distance education environments. Therefore, it might be necessary to analyze internal educational variables (e.g., independence, responsibility, problem solving skills, etc.) and external variables (e.g., online teaching effectiveness, interaction, motivation, literacy of LMS, etc.) which can improve SDL skills for their successful online education.

Especially, the open source e-learning platforms or commercial LMSs are being carefully considered as important educational concepts for successful distance education when the COVID-19 pandemic hits in early 2020. Most higher education institutions as well as public schools should be equipped by the open source e-learning tools/platforms (e.g., Zoom, Google classroom, Skype, Moodle) or need to build up their commercial LMS platforms such as Blackboard, WebCT, and customized learning system. In the midst of COVID-19, which has created geographical and time barriers in the recent education environments, online education through information technologies and LMS can be used to overcome these barriers (Saiyad et al., 2020). Also, Lee and Kim (2020) suggested that schools should be equipped 
with the online learning system (or LMS) to facilitate students' online learning. As a result, distance education and independent learning are becoming important educational concepts to facilitate non face-to-face instructions because of the pandemic of COVID-19 along with the ongoing development of information technologies and online learning-teaching tools/platforms.

The findings of previous researches support that external educational variables in distance education (such as interaction, effective educational design, external motivation, and usage of LMS) may influence predicting SDL level (Chou, 2012; Dixon, 1992; Garrison, 1997; Grandinetti, 2013; Lasfeto \& Ulfa, 2020; Norouzi et al., 2014; Song \& Hill, 2007; Şenyuva \& Kaya, 2015). In addition, online learning-teaching tools/platforms or e-learning LMS platform can be used to overcome the barriers of the COVID-19 pandemic, and can play an important role as a critical mediating variable between effective online education and self-directed learning.

On this basis, this study is to investigate whether online learners' self-directed learning readiness (SDLR) is significantly predicted by external educational factors on the literacy of LMS (LLMS) and self-evaluation online teaching effectiveness (SEOTE). And another critical purpose of this study is to investigate whether there is a significant mediating effect of LLMS between SEOTE and level of SDL. Finally, instructors in distance education should consider key external educational factors such as LLMS and SEOTE to encourage online students to become more self-directed and autonomous.

\section{Research questions}

The following research questions are intended to achieve the purpose of this study.

1. Is there a significant linear relationship between literacy of learning manage system (LLMS) and self-directed learning readiness (SDLR) among online college students?

2. Is there a significant linear relationship between self-evaluation online teaching effectiveness (SEOTE) and SDLR among online college students?

3. Do the predictor variables (SEOTE and LLMS) have significantly different effect on the criterion variable (SDLR)?

4. Does LLMS have a significant mediating effect between SEOTE and SDLR among online college students?

\section{Method}

\subsection{Research design}

For this study, bivariate (Pearson) correlation, multiple linear regression, and mediated regression analysis were conducted. The bivariate correlation was conducted to investigate whether there were any significant linear relationships among SEOTE, 
LLMS, and SDLR. The multiple linear regression was also performed to analyze the significant effects of two predictors (SEOTE and LLMS) when predicting SDLR. In addition, the mediated regression analysis was used to analyze the significant mediating effect of LLMS between SEOTE (IV) and SDLR (DV). For all statistical purposes, an alpha level of .05 was used as the confidence level.

\subsection{Participants}

Participants in this study were online college students taking a class which includes introductory psychology and counseling at the Seoul Cyber University (SCU) in Korea. They also used SCU LMS platform, which SCU developed its own customized learning management system platform in 2011. SCU's LMS platform has several specific features that allow students to engage in almost every activity expected to happen on an offline campus, such as team projects, discussion sessions, online exams, Q \& A boards, and more. SCU's learning management system has also adopted the RIA (rich internet application) technology to customize the lecture content to the students' preferences.

Within the scope of this study, we included 225 students in the fall of 2020. A web survey via Google drive was used. Then we excluded 15 students that did not complete all of web-questionnaires and finally analyzed the data for 210 students (Table 1). Data were collected from November 1st to 20th, 2020.

\section{Instruments}

\subsection{The short-form of self-directed learning readiness (SDLR)}

We used the short-form SDLR scale to look for the effects of motivation, academic stress and age when predicting SDLR in this study (Heo \& Han, 2017). The reduced

Table 1 Characteristics of participants

\begin{tabular}{|c|c|c|c|}
\hline \multicolumn{2}{|l|}{ Characteristics } & \multirow[t]{2}{*}{$n$} & \multirow[t]{2}{*}{$\%$} \\
\hline Variable & Category & & \\
\hline \multirow[t]{2}{*}{ Gender } & Female & 152 & 72.4 \\
\hline & Male & 58 & 27.6 \\
\hline \multirow{4}{*}{$\begin{array}{l}\text { School } \\
\text { Year }\end{array}$} & Freshman & 57 & 27.1 \\
\hline & Sophomore & 8 & 3.8 \\
\hline & Junior & 116 & 55.2 \\
\hline & Senior & 29 & 13.8 \\
\hline \multirow{4}{*}{$\begin{array}{l}\text { Expectation on } \\
\text { Online Learning }\end{array}$} & Very low expectation & 0 & 0 \\
\hline & Low expectation & 5 & 2.4 \\
\hline & Mid expectation & 135 & 64.3 \\
\hline & High expectation & 70 & 33.3 \\
\hline \multicolumn{2}{|l|}{ Total } & 210 & 100 \\
\hline
\end{tabular}


SDLR scale was modified from Guglielmino's original SDLR scale (1997) to measure SDLR levels for online college students.

The original SDLR scale is a 5-point likert scale with 58 items and consists of eight subscales. For this study, we used only 5 subscales and 22 items which include openness to learning opportunities, self-concept as an effective learner, independence in learning, responsibility for one's own learning, and love of learning.

The reliability test of the Korean version of original SDLR scale was Cronbach Alpha's .90 on all 8 subscales (Jeon, 2010). This reduced SDLR scale (22 items) yielded a high coefficient of reliability (Cronbach's alpha $=.89$ ) (Heo \& Han, 2017). In this study, it also showed a high coefficient of reliability, Cronbach's alpha $=.90$.

\subsection{The short form of self-evaluation online teaching effectiveness (SEOTE)}

The SEOTE was developed by Bangert (2006) to assess constructive online teaching practices with seven subscales and a six-point likert scale ranging from strongly agree to strongly disagree. The content validity of this instrument was evaluated by a panel of university professors for clarity, accuracy, and appropriateness of seven effective teaching practices such as a student-faculty contact, cooperation among students, active learning, prompt feedback, time on task, high expectation, and respect for diverse talents and ways of learning (Bangert, 2004). The coefficient alpha of this scale was a high reliability, a coefficient alpha $=.94$ (Bangert, 2008).

In this study, the short form of SEOTE was used (Heo \& Han, 2011). It was developed and modified from the original SEOTE and included twenty-four items. The modified SEOTE has eight subscales after adding new subscale of interest and motivation: (a) Student Faculty Contact (SFC), (b) Cooperation among Students (CAS), (c) Active Learning (AL), (d) Prompt Feedback (PF), (e) Time on Task (TT) or Effective Educational Design (EED), (f) High Expectation (HE), (g) Diverse Talents and Ways of Learning (DTWL), and (h) Interest and Motivation (IM). Scores on this scale range from 24 to 120. The short-form SEOTE is rated on a 5-point likert scale, ranging from always agree to always disagree. It revealed a high coefficient of reliability (Cronbach's alpha $=.96$ ) (Heo \& Han, 2011). In this study, the coefficient of reliability was Cronbach's alpha $=.97$.

\subsection{The literacy of learning manage system (LLMS)}

The Cronbach's alphas of the modified 'the survey of self-regulated learning competency' (SSLC) in eight realms (LLMS utilization, learning-motivation, goal-setting, time-management, learning duration, effort-attribution evaluation, self-reflection, satisfaction of class with LMS) were ranged from .63 to .94 (Jeon et al., 2016). In this study, the short-form LLMS which is one realm of eight sub-scales for SSLC was used. It showed a high coefficient of reliability (Cronbach's alpha $=.88$ ). 
Table 2 Correlation between $\mathrm{IVs}^{\mathrm{a}}$ and $\mathrm{DV}^{\mathrm{a}}$

\begin{tabular}{lllllll}
\hline Variable & SDLR-1 $^{\mathrm{b}}$ & SDLR-2 $^{\mathrm{b}}$ & SDLR-3 $^{\mathrm{b}}$ & SDLR-4 $^{\mathrm{b}}$ & SDLR-5 $^{\mathrm{b}}$ & Total of SDLR $^{\mathrm{b}}$ \\
\hline SEOTE & $.464 * *$ & $.382^{* *}$ & $.391^{* *}$ & $.420^{* *}$ & $.388^{* *}$ & $.524 * *$ \\
LLMS & $.393^{* *}$ & $.390^{* *}$ & $.366^{* *}$ & $.356^{* *}$ & $.378^{* *}$ & $.487^{* *}$ \\
\hline
\end{tabular}

$* * p<.01$

${ }^{\mathrm{a}}(\mathrm{IV} s=$ SEOTE, LLMS; DV $=$ SDLR $)$

b(SDLR-1 = openness to learning opportunities; SDLR-2 = self-concept as an effective learner; SDLR-2 = independence in learning; SDLR-4 = responsibility for one's own learning; SDLR-5 = love of learning; Total of SDLR = total score of self-directed learning readiness)

\section{Results}

\subsection{Effects of a set of SEOTE and LLMS on SDLR}

This study used a bivariate (Pearson) correlation to analyze between SEOTE and SDLR (Table 2). Research had shown that there was a significant positive relationship between SEOTE and SDLR $(r(208)=.524, p<.01)$. SEOTE also revealed significant correlations with the SDLR's 5 subscales (openness to learning opportunities: $r=.464, p<.01$; self-concept as an effective learner: $r=.382, p<.01$; independence in learning: $r=.391, p<.01$; responsibility for one's own learning: $r=.420, p<.01$; love of learning: $r=.388, p<.01)$.

A bivariate (Pearson) correlation between LLMS and SDLR was also conducted (Table 2). There was a significant positive correlation $(r(208)=.487, p<.01)$. LLMS also had significant linear relationships with SDLR's 5 subscales (openness to learning opportunities: $r=.393, p<.01$; self-concept as an effective learner: $r=.390$, $p<.01$; independence in learning: $r=.366, p<.01$; responsibility for one's own learning: $r=.356, p<.01$; love of learning: $r=.378, p<.01$ ).

\subsection{Effects of SEOTE and LLMS on predicting SDLR}

To predict SDLR, multiple regression by stepwise method to determine the accuracy of the SEOTE and LLMS was conducted. Data were screened to test research questions, excluding missing data and outliers. There were no missing values and outliers which exceeded the critical value of Chi-square that were significant at $p<.001$ with the respective degree of freedom. After that, normality and linearity for multivariate were analyzed by generating a scatter-plot matrix. To assess homoscedasticity, the residual plot was analyzed. The scatter-plots in the matrix were almost elliptical and residual plot was scattered but was not extreme. In addition, the Box test of equality was conducted to test the homoscedasticity for multivariate. The significance was not found at .05 or .01 . Thus, the assumptions for normality, linearity, and homoscedasticity were satisfied. All tolerances for SEOTE and LLMS were above .1 and all VIF (variance inflation factors) were less than 10 (Table 3). Therefore, there was no collinearity problem. 
Table 3 Multiple linear regression analysis using the stepwise method

\begin{tabular}{|c|c|c|c|c|c|c|c|c|c|}
\hline Model & Variable & B & $\beta$ & $t$ & Tolerance & VIF & $F$ & $R^{2}$ & $R_{a d j}^{2}$ \\
\hline \multirow[t]{4}{*}{1} & (constant) & 2.71 & & $18.76^{* * * *}$ & & & $* 78.78 * * *$ & .275 & .271 \\
\hline & SEOTE & .34 & .52 & $8.88 * * *$ & 1.00 & 1.00 & & & \\
\hline & Excluded v & iable & & & & & & & \\
\hline & LLMS & & .26 & $3.42 * *$ & .59 & 1.69 & & & \\
\hline \multirow[t]{3}{*}{2} & (constant) & 2.72 & & $19.29 * * *$ & & & $47.28 * * *$ & .314 & .307 \\
\hline & SEOTE & .23 & .36 & $4.81 * * *$ & .59 & 1.69 & & & \\
\hline & LLMS & .13 & .26 & $3.42 * *$ & .59 & 1.69 & & & \\
\hline
\end{tabular}

$* * p<.01 ; * * * p<.001$

Multiple linear regression analysis using the stepwise method (Table 3) revealed that the predictor (SEOTE) in the first model did have significantly effect on predicting the level of SDLR and accounted for $27.5 \%$ of variance in SDLR, $R^{2}=.275$, $R_{\text {adj }}^{2}=.271, F(1,208)=78.78, p<.001$. The multiple linear regression analysis for predicting SDLR represented that the predictors of SEOTE and LLMS in the second model significantly predicted the level of SDLR, $R^{2}=.314, R_{\text {adj }}^{2}=.307, F(2$, $207)=47.28, p<.001$. Also, the second model of two predictors adding $3.9 \%$ of $R^{2}$ change accounted for $31.4 \%$ of SDLR's variance and two variables (SEOTE's $\beta=.36$, $t(207)=4.81, p<.001$; LLMS's $\beta=.26, t(207)=3.42, p<.01)$ significantly contributed to this model (two predictors of SEOTE and LLMS, criterion of SDLR). Consequently, the results of the multivariate regression analysis revealed that SEOTE and LLMS did have a significant influence on predicting SDLR's level.

\subsection{Mediating effect of LLMS between SEOTE and SDLR}

In order to test the mediating effect of LLMS between SEOTE (IV) and SDLR (DV), mediated regression analysis was applied according to the method suggested by Baron and Kenny (1986). The result of mediated regression analysis for the mediator of LLMS between SEOTE and SDLR was shown in Table 4.

The first step was to take SEOTE as an independent variable and LLMS as a dependent variable or mediator variable. The standardized regression coefficient of independent variable was significant $(\beta=.64, t(208)=11.99, p<.001)$ and SEOTE

Table 4 Mediating effect of LLMS for online college students

\begin{tabular}{llllllllllll}
\hline Step & IV & DV & $\boldsymbol{B}$ & $\boldsymbol{S E}$ & $\boldsymbol{\beta}$ & $\boldsymbol{t}$ & tolerance & VIF & $\boldsymbol{F}$ & $\boldsymbol{R}^{\mathbf{2}}$ & $\boldsymbol{R}^{\mathbf{2}}$ adj \\
\hline 1 & SEOTE & LLMS & .81 & .068 & .64 & $11.99^{* * *}$ & 1.00 & 1.00 & $143.86^{* * * *}$ & .409 & .406 \\
2 & SEOTE & SDLRS & .34 & .038 & .52 & $8.88^{* * *}$ & 1.00 & 1.00 & $78.78^{* * *}$ & .275 & .271 \\
3 & SEOTE & SDLRS & .23 & .049 & .36 & $4.81^{* * *}$ & .59 & 1.69 & $47.28^{* * *}$ & .314 & .307 \\
& LLMS & & .13 & .038 & .26 & $3.42^{* *}$ & .59 & 1.69 & & & \\
\hline
\end{tabular}

$* * p<.01 ; * * * p<.001$ 
Table 5 Mediating effect test of LLMS

\begin{tabular}{lll}
\hline Relationship among Variables & Sobel Test $/ \mathrm{z} /$ & Sig. \\
\hline $\mathrm{a} \rightarrow \mathrm{b} \rightarrow \mathrm{c}$ & 5.48 & .000 \\
\hline
\end{tabular}

a. self-evaluation online teaching effectiveness; SEOTE, b. literacy of learning manage system; LLMS, c. self-directed learning readiness; SDLR

accounted for $40.9 \%$ of variance of LLMS, $F(1,208)=143.86, p<.001$. Therefore, SEOTE had significantly effect on the dependent variable of LLMS.

The second step was to take SEOTE as an independent variable and SDLR as a dependent variable. SEOTE significantly accounted for $27.5 \%$ of the variance of SDLR, $R^{2}=.275, R_{\text {adj }}^{2}=.271, F(1,208)=78.78, p<.001$. The $\beta$ coefficient of SEOTE was significant, $\beta=.52, t(208)=8.88, p<.001$. Thus, SEOTE was significantly influential in predicting SDLR.

The third step was to take SEOTE and LLMS as independent variables and SDLR as a dependent variable. The standardized regression coefficient of SEOTE was significant $(\beta=.36, t(207)=4.81, p<.001)$. Also, the standardized $\beta$ coefficient of LLMS was significant $(\beta=.26, t(207)=3.42, p<.01)$. This model of two IVs significantly predicted the SDLR, $R^{2}=.314, R_{\text {adj }}^{2}=.307, F(2,207)=47.28, p<.001$. Therefore, SEOTE and LLMS were significantly influential in predicting SDLR.

The $\beta$ coefficient of SEOTE in the step 2 and 3 was compared in the last step. The $\beta$ coefficient of SEOTE was decreased as LLMS was added between SEOTE and SDLR. In other words, the $\beta$ coefficient of SEOTE in the step $3(\beta=.36)$ was lower than the $\beta$ value of SEOTE in the step $2(\beta=.52)$. As a result, LLMS had a significant mediating

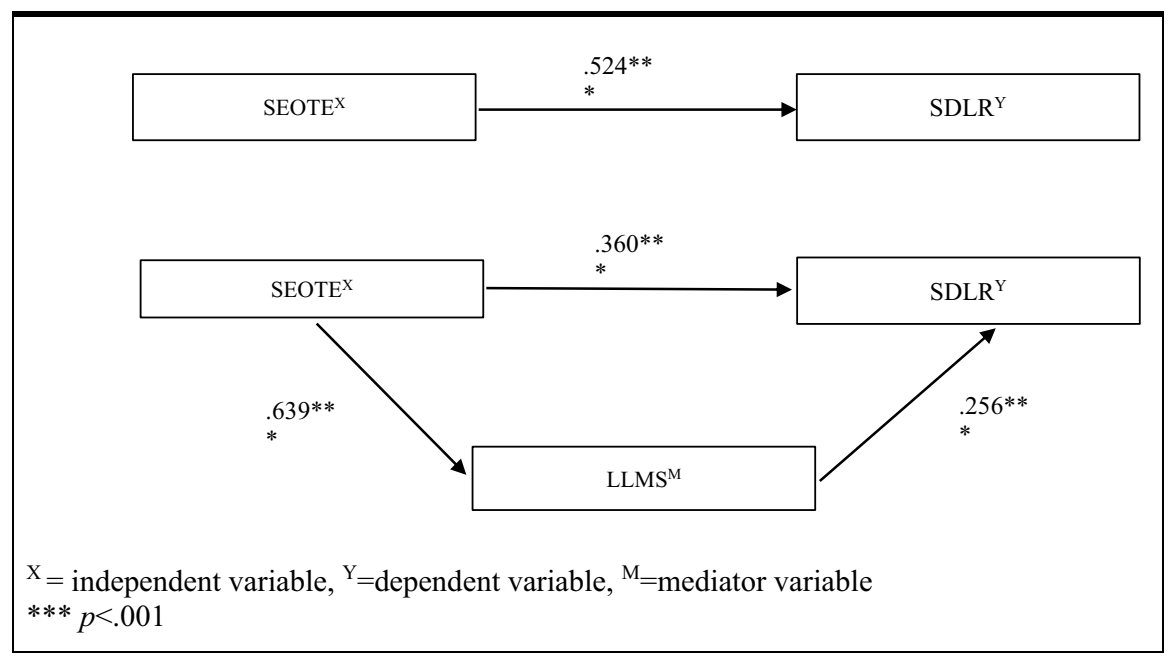

Fig. 1 Mediating effect of LLMS between SEOTE and SDLR 
effect as SEOTE did have a significant effect on SDLR according to the method of Baron and Kenny (1986).

The Sobel test was used to investigate whether LLMS significantly carries the influence of SEOTE on SDLR. And the test results was shown in the Table 5. LLMS between SEOTE and SDLR was significant $(/ z /=5.48, p<.001)$. Thus, LLMS had significant mediating effect SEOTE did have an effect on SDLR. There was a significant indirect effect of SEOTE and LLMS on SDLR. The specific path of mediating effect is shown in the Fig. 1.

\section{Conclusion and discussion}

This study showed some important conclusions drawn from 4 research questions. In terms of the first research question, it revealed a significant positive relationship between SEOTE and SDLR's level. This finding was consistent with what Saiyad et al. (2020) maintained that online teaching can help students develop self-directed learning skills, and that good online teaching must encourage development of self-directed learning for online students. Therefore, good instructors can improve their online teaching effectively in order to enhance their online students' SDLR. In addition, the higher level of SDL can be significantly influenced by students' social interaction, effective design, motivation which are related to the effectiveness of online learning and teaching (Grandinetti, 2013; Heo \& Han, 2017; Lasfeto \& Ulfa, 2020). In other words, students can plan a very selfdirected and autonomous online learning when instructors can design their online teaching in terms of interaction, prompt feedback, effective design, interest and motivation.

Regarding the research question two, it explained that there was a positive relationship between LLMS and SDLR's level. The positive relationship between LLMS and SDLR implied that SDLR's level among online students improved when fluent use of learning manage systems for online learning was possible. This result was congruent with previous researches that LMS can provide online students with self-directed learning and promote the self-directed learning (Angriani \& Nurcahyo, 2019; Biney, 2020; Norouzi et al., 2014; Song \& Hill, 2007; Tredoux, 2012). Norouzi et al. (2014) revealed that there were significant differences between the control and experimental groups after two semesters in the SDL post-test. Therefore, usage of LMS had a significant influence on SDL's level. Research had shown that online college students with high LLMS had a high SDLR's level. For these reasons, it is critical that online instructors have to encourage student to use LMS proficiently so as to encourage SDL in an online learning environment.

With regard to research question three, SEOTE and LLMS had a significant impact on predicting SDLR level among online students. In other words, online students can improve their SDL levels by using LMS fluently, which provided them with an effective online teaching with interaction, prompt feedback, effective design, interest and motivation. Besides, online teaching effectiveness was the highest correlation in predicting SDLR. Previous researches also revealed that the web-based learning did affect positively the self-directed learning (Chou, 
2012; Chou \& Chen, 2008; Khalid et al., 2020; Rashid \& Asghar, 2016; Saxena, 2013; Şenyuva \& Kaya, 2015). Especially, Jeon et al. (2016) maintained that the continuous usage of LMS had a significant influence on the self-regulated learning ability. For these reasons, instructors need to improve efficiently online teaching in terms of interaction, prompt feedback, effective educational design, interest and motivation and encourage their students to use the LMS fluently for high level of self-directed learning in the web-based learning.

Lastly, LLMS had a significant mediating effect as SEOTE did have a significant effect on SDLR. In addition, there was a significant indirect effect of SEOTE and the mediator variable (LLMS) on SDLR. Several studies for the development of LMS models in self-directed learning had shown that the use of self-directed learning management systems improved self-directed learning ability in an online learning environments (Kim \& Lee, 2014; Norouzi et al., 2014). These findings partially supported that the level of SDLR can be directly and/or indirectly affected by the effective online teaching and the usage of LMS as a mediator between online teaching effectiveness and level of self-directed learning. Therefore, LMS can be designed and used to enhance the self-directed learning in an effective distance education and teaching environments for students.

\section{Recommendation and limitation}

This study revealed that there were significant positive relationships between a set of variables (i.e., SEOTE and LLMS) and SDLR level. These results encouraged online educators to improve online students' SDL by urging them to use LMS fluently and improve online teaching effectiveness in terms of interaction, feedback, effective educational design, and motivation. In addition, instructors need to play an important role as educational designers to efficiently design self-directed LMS which enhanced students' SDL, taking into account the proper use of synchronous/ asynchronous online teaching-learning tools/platforms.

This study also showed that SEOTE and LLMS influenced predicting SDLR level. There were also significant mediating effect of LLMS between SEOTE and SDLR. In other words, SEOTE had a significant effect on the mediator of LLMS. And the mediator variable, in turn, was significantly influential in SDLR. Therefore, online educators definitely need to figure out the influences of effective online teaching and LMS platform for online students' SDL. Self-directed learners can be more independent and autonomous in the online education environment once online educators effectively improve online teaching through ICT and motivate online learners to use self-directed LMS platform by considering the mediating effect of LMS between SEOTE and SDL. This means that online educators can contemplate the educational activities and elements (i.e., interaction, cooperation, feedback, motivation, active learning) needed in an online educational environment to enhance the online teaching effectiveness. And then, they can design and plan a customized LMS platform using a variety of asynchronous/synchronous online teaching-learning tools/platforms. Consequently, 
the LMS platform will provide self-directed learning to online learners as a crucial mediator between effective online teaching and self-directed learning.

This study may be limited to considering the effectiveness of LMS with various asynchronous/synchronous online teaching-learning tools/platform as well as open source/customized online learning systems (or LMS). Lee and Kim (2020) reported that the level of satisfaction for synchronous online classes was slightly higher than that of asynchronous online classes. Therefore, further research will be required to analyze whether the different types of LMS according to synchronous/asynchronous online teaching-learning tools/platforms have a significant impact on online students' SDL, learning satisfaction, or motivation in an online educational environment.

\section{References}

Angriani, P., \& Nurcahyo, H. (2019). The influence of moodle-based e-learning on self-directed learning of senior high school students. AIP Publishing, 2120(1), 1-6.

Allen, I. E., \& Seaman, J. (2016). Online report card: Tracking online education in the United States. Retrieved September 18, 2020 from https://files.eric.ed.gov/fulltext/ED572777.pdf.

Bangert, A. W. (2004). The seven principles of effecting teaching: A framework for evaluating on-line teaching. The Internet and Higher Education, 7, 217-232.

Bangert, A. W. (2006). The development of an instrument for assessing online teaching effectiveness. Journal of Educational Computing Research, 35(3), 227-244.

Bangert, A. W. (2008). The development and validation of the student evaluation of online teaching effectiveness. Computers in the Schools, 25, 25-47.

Baron, R. M., \& Kenny, D. A. (1986). The moderator-mediator variable distinction in social psychological research: conceptual, strategic, and statistical consideration. Journal of Personality and Social Psychology, 51, 1173-1182.

Biney, I. K. (2020). Experience of adult learners using Sakai Learning Management System in learning in Ghana. Journal of Adult and Continuing Education, 26(2), 262-282.

Chou, P., \& Chen, W. (2008). Exploratory study of the relationship between self-directed learning and academic performance in a web-based learning environment. Online Journal of Distance Learning Administration, 11(1), 22-27.

Chou, P. (2012). Effect of students' self-directed learning abilities on online learning outcomes: Two exploratory experiments in electronic engineering. International Journal of Humanities and Social Sciences, 2, 172-179.

Cyber University Information. (2019). The state of cyber universities. Retrieved August 16, 2019 from http://www.cuinfo.net/home/eudc/statistics.sub.action?gnb=55\&gubunNm=univ\&sttYear=2019.

Dixon, W. B. (1992). An exploratory study of self-directed learning readiness and pedagogical expectations about learning among adult inmate learners in Michigan. (Doctoral dissertation). Michigan state university, MI.

Garrison, D. R. (1997). Self-directed learning: Toward a comprehensive model. Adult Education Quarterly, 48, 18-33.

Grandinetti, M. (2013). Motivation to learn, learner independence, intellectual curiosity and self-directed learning readiness of pre-licensure sophomore baccalaureate nursing students. (Doctoral dissertation). Widener university, Chester.

Hematian, F., Rezaei, A. M., \& Mohammadyfar, M. A. (2017). On the effect of goal setting in selfdirected learning, achievement motivation, and academic achievement among Students. Modern Applied Science, 1(1), 37-47.

Heo, J., \& Han, S. (2011). The college students' satisfaction related to expectation and interaction in the online counseling courses. Educational Technology International, 12(2), 117-134.

Heo, J., \& Han, S. (2017). Effects of motivation, academic stress and age in predicting self-directed learning readiness (SDLR): Focused on online college students. Education and Information Technologies, 22(84), 1-11. 
Howell, S., Williams, P., \& Lindsay, N. (2003). Thirty-two trends affecting distance education: An informed foundation for strategic planning. Retrieved August 13, 2019, from http://www.westga. edu/ distance/ojdla/fall63/howell63.html

Jeon, G. (2010). The effects of an e-learning information literacy instruction program on self-directed learning ability of university student (Master's dissertation). University of Soongsil.

Jeon, Y., Kim, K., \& Cho, J. (2016). A study on the effect of LMS on the self-regulated learning competency and learning satisfaction in higher education. Journal of Korean Association for Educational Information and Media, 22(1), 55-84.

Khalid, M., Bashir, S., \& Amin, H. (2020). Relationship between self-directed learning (SDL) and academic achievement of university students: A case of online distance learning and traditional universities. Bulletin of Education and Research, 42(2), 131-148.

Kim, H., \& Lee, J. (2014). Effects of cyber universities career maturity on academic stress: Mediator effects of self-directed learning readiness. The Korea Contents Association, 14(11), 486-496.

Lasfeto, D. B., \& Ulfa, S. (2020). The relationship between self-directed learning and students' social interaction in the online learning environment. Journal of e-learning and knowledge society, 16(2), 34-41.

Lee, D., \& Kim, M. (2020). University students' perceptions on the practices of online learning in the COVID-19 situation and future direction. Multimedia-Assisted Language Learning, 23(3), 359-377.

Lemmetty, S., \& Collin, K. (2019). Self-directed learning as a practice of workplace learning: Interpretative repertoires of self-directed learning in ICT. Vocational and Learning, 13, 47-70.

Ministry of Culture, Sports and Tourism. (2018). K-MOOC (Korean Massive Open Online Courses). Retrieved February 23, 2021 from https://www.korea.kr/special/policyCurationView.do?newsId= 148866901

National Institute for Lifelong Education. (2021). Korean massive open online course(K-MOOC). Retrieved February 23, 2021 from https://www.nile.or.kr/contents/contents.jsp?bkind=html\& bcode $=$ HABAAAA\&bmode $=$ view $\&$ id $=$ HABAAAA

Norouzi, M., Hamid, D. H. T. B. A., Samet, A., \& Ranmezani, S. (2014). Model of learning management system for self-directed learning. International Journal of Information Dissemination and Technology, 4(4), 332-337.

Rashid, T. \& Asghar, H. M. (2016). Technology use, self-directed learning, student engagement and academic performance: Examining the interrelations. Computers in Human Behavior, 63, 604-612.

Rivenburg, C. R. (2015). Instructional design strategies and their effect on self-directed learning in online learning. (Doctoral dissertation). Capella university, MN.

Saiyad, S., Virk, A., Mahajan, R., \& Singh, T. (2020). Online teaching in medical training: Establishing good online teaching practices from cumulative experience. International Journal of Applied Basic Medical Research, 10(3), 149-155.

Saxena, S. (2013). How technology support self-directed learning. Retrieved March 1, 2021, from https:// edtechreview.in/news/824-how-technology-supports-self-directed-learning

Şenyuva, E., \& Kaya, H. (2015). The correlation between self-directed learning readiness and web-based learning in nursing students: A study conducted in Turkey. The New Educational Review, 41(3), 98-107.

Sirakaya, D. A., \& Ozdemir, S. (2018). The effect of flipped classroom model on academic achievement, self-directed learning readiness, motivation and retention. Malaysian Online Journal of Educational Technology, 6(1), 76-91.

Song, L., \& Hill, J. R. (2007). A conceptual model for understanding self-directed learning online environments. Journal of Interactive Online Learning, 6(1), 27-42.

Tredoux, C. (2012). The potential of a learning management system to enhance self-directed learning. (Doctoral dissertation). North-West University, South Africa.

Zimmerman, B. J., \& Kitsantas, A. (2005). The hidden dimension of personal competence: Self-regulated learning and practice. In A. J. Elliot \& C. S. Dweck (Eds.), Handbook of competence and motivation (pp. 509-526). The Guilford Press.

Publisher's Note Springer Nature remains neutral with regard to jurisdictional claims in published maps and institutional affiliations. 